Građevinski materijali i konstrukcije

Building Materials and Structures

journal homepage: www.dimk.rs

doi: 10.5937/GRMK2104251P UDK: 624.014 .2

Preliminary report

\title{
Strength enhancement of cold-formed steel tubular column using GFRP strip subjected to axial compression
}

\author{
Sangeetha Palanivelu ${ }^{* 1}$, Dhinagaran Moorthy ${ }^{1)}$, Gobinaath Subramani ${ }^{1)}$, Jeevan Raj Dhayanithi ${ }^{1)}$ \\ 1) Department of Civil Engineering, Sri Sivasubramaniya Nadar College of Engineering, Chennai, Tamil Nadu, India
}

\section{Article history}

Received: 22 April 2021

Received in revised form:

21 September 2021

Accepted: 15 October 2021

Available online: 30 December 2021

Keywords

Cold-formed steel

tubular column,

glass fibre strip,

ANSYS,

failure mode

\begin{abstract}
The experimental and analytical evaluation of externally reinforced square and circular cold-formed steel tubular columns with GFRP strips is presented in this study. Under axial compression, fourteen tubular columns with pinned support, seven square tubular sections, and seven circular hollow section columns with externally bonded GFRP strips at various points were tested to failure. The GFRP strips improved the load-carrying capacity of the columns according to the trial results. The GFRP strip at the ends and intermediate regions, with a clear spacing of 100 to $150 \mathrm{~mm}$ between the strips, has been proven to be the most effective in achieving ultimate strength, especially for column specimens with full wrapping. Wrapping the GFRP strips increases the strength of square and circular columns by $24 \%$ and $5 \%$, respectively, when compared to unwrapped specimens. The percentage gain in strength is $16 \%$ when the cross-section is changed from circular to square. Local and overall flexural buckling, respectively, are the failure modes seen in the square and circular sections. The experimental strength and axial deformation were compared to the analytical results, which showed a satisfactory correlation.
\end{abstract}

List of symbols

D Diameter of the circular column" $m$ "

b Breadth of the square column" $\mathrm{mm}$ "

d Depth of the square column" $\mathrm{mm}$ "

$\mathrm{h}$ height of column "mm"

$t$ thickness of the section "mm"

$\mathrm{s} \quad$ clear spacing between the fibre strip " $\mathrm{mm}$ "

PANSYS Finite element ultimate load "kN"

$P_{\text {EXP }} \quad$ Experimental ultimate load "kN"

$\triangle_{\text {ANSYS }} \quad$ Finite element axial deformation " $\mathrm{mm}$ "

$\triangle_{\text {EXP }} \quad$ Experimental axial deformation " $\mathrm{mm}$ "

$\begin{array}{ll}\text { Subscripts } \\ \text { ST } & \text { Square Tube } \\ \text { CT } & \text { Circular Tube } \\ \text { EW } & \text { End Wrap } \\ \text { IW } & \text { Intermediate Wrap } \\ \text { FW } & \text { Full Wrap } \\ \text { NW } & \text { No Wrap } \\ \text { CFST } & \text { Cold-Formed Steel Tube } \\ \text { GFRP } & \text { Glass Fibre Reinforced Polymer } \\ \text { CFRP } & \text { Carbon Fibre Reinforced Polymer } \\ \text { EXP } & \text { Experimental } \\ \text { ANSYS } & \text { Finite element software }\end{array}$

experiments using five different commercially available adhesives. The lap shear strength between the tube and the fibre [3] was determined by testing very high strength buttwelded circular steel tubes strengthened with CFRP. Experimentally, a series of tests on reinforcing circular hollow steel tube sections with high modulus CFRP sheets with various bond lengths and layer counts were conducted[4]. Design curves for predicting the capacity of short CFRPreinforced steel tubular columns in axial compression [5]. A state-of-the-art review of FRP-strengthened steel structures identifies existing research on the subject as well as future research on confined columns [6]. Cold-formed steel channel section confined with CFRP strips wrapped over the web and flange subjected to eccentric compression: experimental and analytical results [7]. The application of

Corresponding author:

E-mail address: sanqeethap@ssn.edu.in 
FRP in the strengthening of steel structures is dependent on several factors, including surface preparation for bonding, adhesive selection, flexural and fatigue strength of steel structures, and so on[8]. Using EC3 and AISI specifications, the ultimate strength of CFRP wrapped cold-formed steel lipped channel columns was calculated [9]. Punitha Kumar and R. Senthil [10,11], Jai-Woo Park et al [12], Amr Shaat and Amir Z.Fam [13], and Masoumeh Karimian et al [14] are only a few of the researchers who have looked into steel column strengthening using CFRP and GFRP. Generally, thin-walled sections show deformation before yielding the cross-section whereas the thick-walled sections show deformation after yielding of the cross-section. It was expected that FRP sheets confined column sides, control the outward buckling but not the inward buckling [15]. The inward and outward buckling failure of the short column are shown in Figure 1.

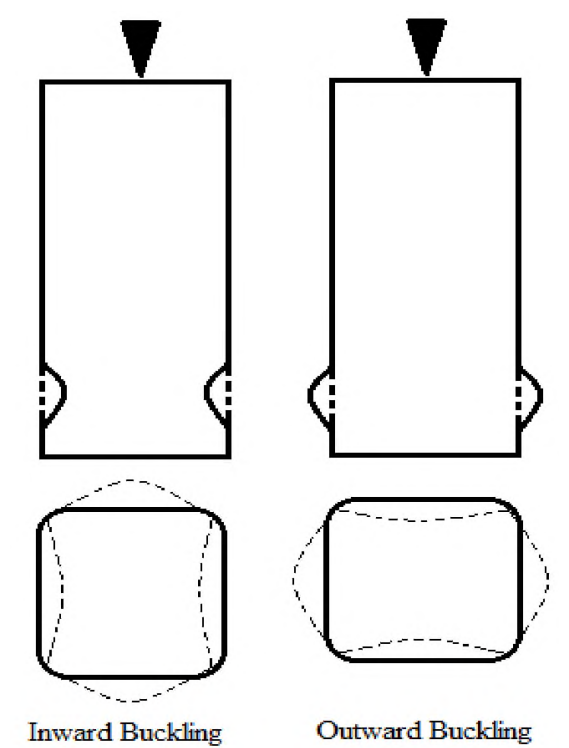

Fig. 1. General failure mode of short column

The behaviour of cold-formed steel tubular columns enhanced with GFRP strips at various positions was reported in this study. The cross section of the tubular column and the position of the GFRP strips were both changed in the investigation. All the columns were tested to failure under axial compression The ultimate load-bearing capacity, maximum axial deflection, axial strain, and failure modes were all investigated.

\section{Experimental program}

\subsection{Fabrication of the column specimen}

The specimen was fabricated using cold-formed steel of grade St 34-1079 by IS 1079-2009 specifications. The coldformed steel square and circular tubular members were cut into lengths of $800 \mathrm{~mm}$ using a computerised cutting machine. The slenderness ratio is defined as the ratio between the length of the column to its lateral dimension and it is 10.6 for both square $(\mathrm{h} / \mathrm{d}=800 / 75)$ and circular ( $h / D=800 / 75$ ) cross-section of the tubular member was maintained for comparison. The hollow tubular columns were wrapped with GFRP in the form of strips and tested to failure under axial compression. The coupon test was conducted to study the material properties like yield stress, ultimate stress, modulus of elasticity and elongation of specimen after fracture and they are determined as $267 \mathrm{~N} / \mathrm{mm}^{2}, 475 \mathrm{~N} / \mathrm{mm}^{2}$, $2.04 \times 10^{5} \mathrm{~N} / \mathrm{mm}^{2}$, and $48 \mathrm{~mm}$ respectively. The manufacturer data of GFRP sheets gives that the thickness, tensile strength, tensile modulus, elongation after fracture and mass density thickness are $1 \mathrm{~mm}, 1724 \mathrm{MPa}, 76 \mathrm{GPa}$, $2.8 \%$, and $2500 \mathrm{~kg} / \mathrm{m}^{2}$ respectively. The specimen details and its dimensions are shown in Figure 2 and Table.1.

Before the compression test on column specimens, the outer surface of the CFST columns was cleaned by sandpaper to remove the rust and debris and rough the surface of the column to improve the interlocking property between the steel and the adhesive. For wrapping of GFRP sheet with steel, an epoxy resin Araldite® GY 257 was used. The GFRP strips of wide $100 \mathrm{~mm}$ were bonded onto the column specimen and its position is shown in Figure 2. Table.1 also describes measured dimensions of the specimens, the position of the GFRP strip and its clear spacing between the strip. The specimen identification was made as ST - Square Tube, CT - Circular Tube, NW - No Wrap, FW- Full Wrap, IW- Intermediate Wrap and EW- End Wrap. The specification of one specimen from Table. 1, ST $-2 \mathrm{IW}-\mathrm{EW}$ is the Square tubular section wrapped with two intermediate GFRP strips along with the end strip.

Table 1. Paremetres of the CFS wrapped column specimen

\begin{tabular}{|c|c|c|c|c|c|c|c|}
\hline Specimen ID & $\begin{array}{c}\mathrm{h} \\
(\mathrm{mm})\end{array}$ & $\begin{array}{c}\mathrm{b} \\
(\mathrm{mm})\end{array}$ & $\begin{array}{c}\mathrm{d} \\
(\mathrm{mm})\end{array}$ & $\begin{array}{c}D \\
(\mathrm{~mm})\end{array}$ & $\begin{array}{c}\mathrm{t} \\
(\mathrm{mm})\end{array}$ & $\begin{array}{c}\mathrm{s} \\
(\mathrm{mm})\end{array}$ & Position of the fiber strip \\
\hline ST - NW & 801 & 75 & 75 & - & 2 & - & - \\
\hline $\mathrm{ST}-1 \mathrm{IW}$ & 802 & 75 & 75 & - & 2 & - & Intermediate strip \\
\hline ST $-2 \mathrm{IW}$ & 800 & 75 & 75 & - & 2 & 400 & Intermediate strip \\
\hline$S T-E W$ & 802 & 75 & 75 & - & 2 & 600 & End strip \\
\hline$S T-1 \mathrm{IW}-\mathrm{EW}$ & 801 & 75 & 75 & - & 2 & 250 & Intermediate + End strip \\
\hline ST - 2IW - EW & 803 & 75 & 75 & - & 2 & 133 & Intermediate + End strip \\
\hline ST - FW & 801 & 75 & 75 & - & 2 & - & Full strip \\
\hline CT - NW & 802 & - & - & 75 & 2 & - & - \\
\hline$C T-1 I W$ & 800 & - & - & 75 & 2 & - & Intermediate strip \\
\hline$C T-2 \mathrm{IW}$ & 801 & - & - & 75 & 2 & 400 & Intermediate strip \\
\hline $\mathrm{CT}-\mathrm{EW}$ & 803 & - & - & 75 & 2 & 600 & End strip \\
\hline$C T-1 I W-E W$ & 802 & - & - & 75 & 2 & 250 & Intermediate + End strip \\
\hline$C T-2 \mathrm{IW}-\mathrm{EW}$ & 801 & - & - & 75 & 2 & 133 & Intermediate + End strip \\
\hline $\mathrm{CT}-\mathrm{FW}$ & 800 & - & - & 75 & 2 & - & Full strip \\
\hline
\end{tabular}

${ }^{*} \mathrm{~h}$-Height of column, $\mathrm{b}$ and $\mathrm{d}-$ breadth and depth of the square tube, D- diameter of the circular tube, t-thickness of the cold formed steel and s - clear spacing between GFRP strip 


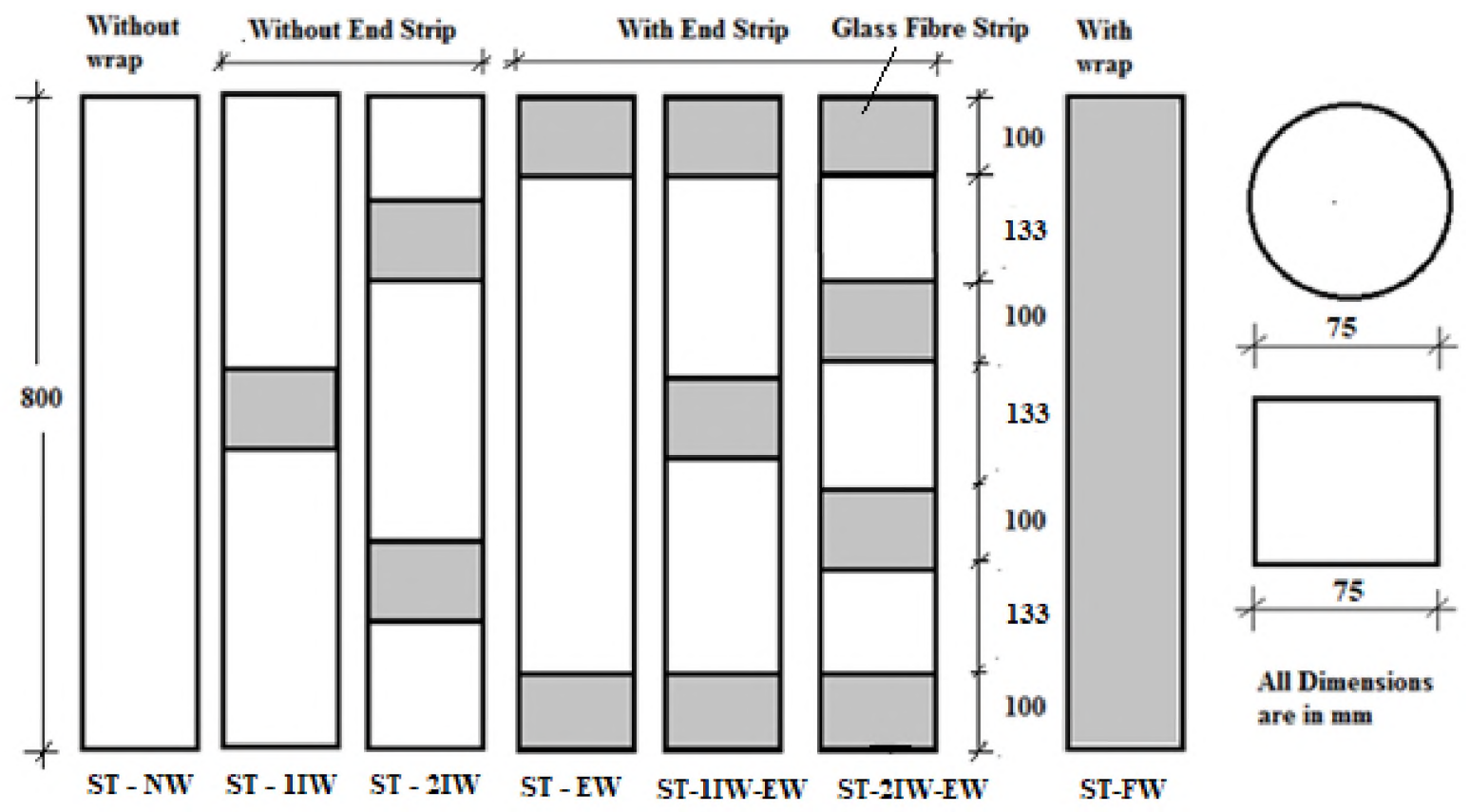

Fig. 2. Details of the CFS wrapped column specimen

\subsection{Test setup and Instrumentation}

All column specimens were tested to failure under axial compression using a Universal Testing Machine(UTM) of capacity $600 \mathrm{kN}$. The static load was applied at a rate of 0.5 $\mathrm{mm} / \mathrm{min}$ using hydraulic stroke control[16]. The end of the columns was welded with end plates to achieve pinned support condition. The lateral and axial deflections were measured using two dial gauges having the least count of $0.01 \mathrm{~mm}$. The position of the dial gauges to measure the axial deformation and lateral deformation at mid-height of the specimen are shown in Figure 3. The longitudinal strain at the mid-height of the specimen was recorded using a $20 \mathrm{~mm}$ strain gauge which attached directly to the column specimens either on the steel surface or the fiber surface. The strain values were recorded using a 5-channel strain indicator as shown in Figue 3. The deformation and strain were measured at every $10 \mathrm{kN}$ load interval and all the column specimens were tested until it reaches the maximum load. Figure 3 shows the schematic test setup and experimental test setup.
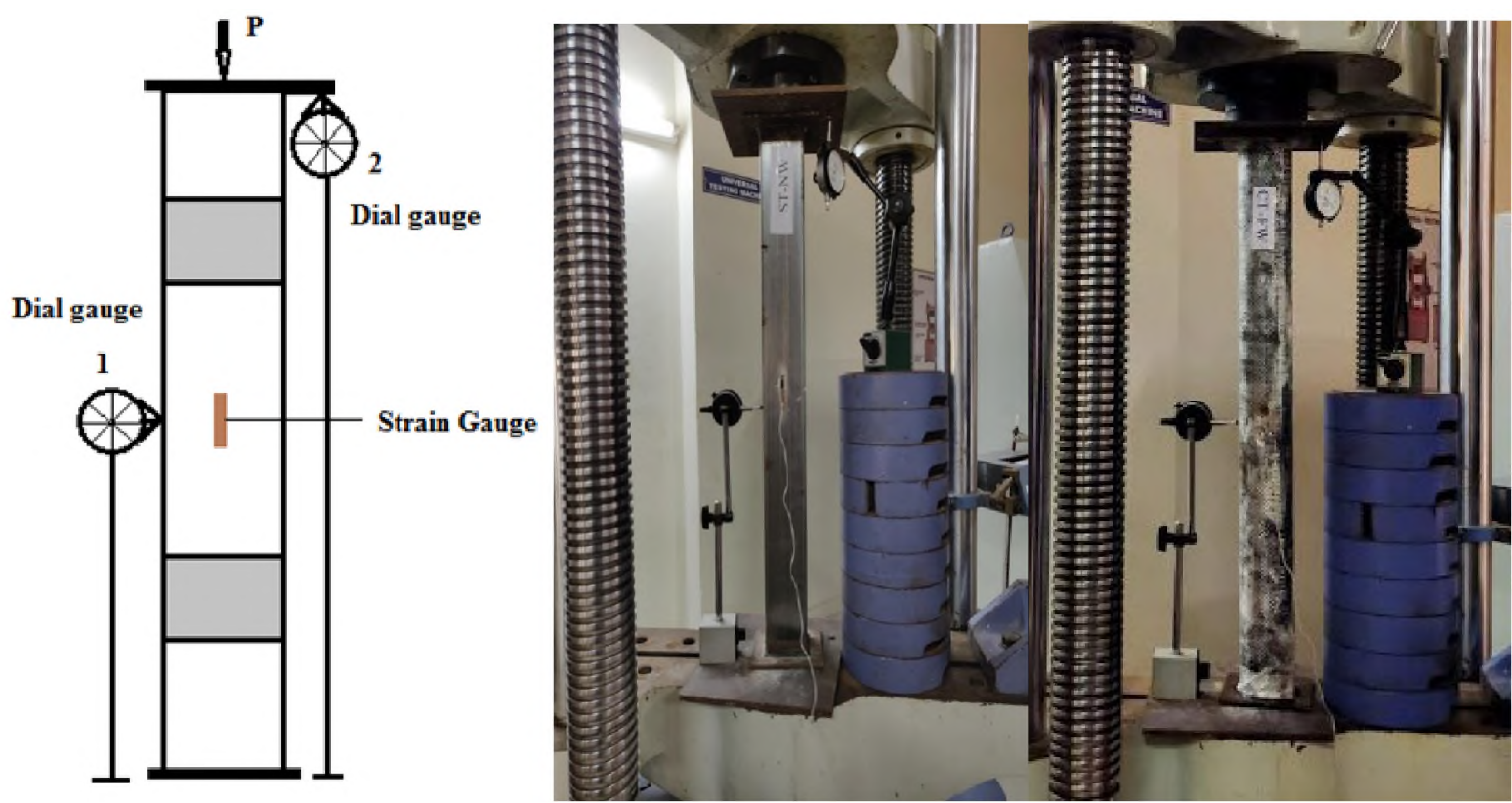


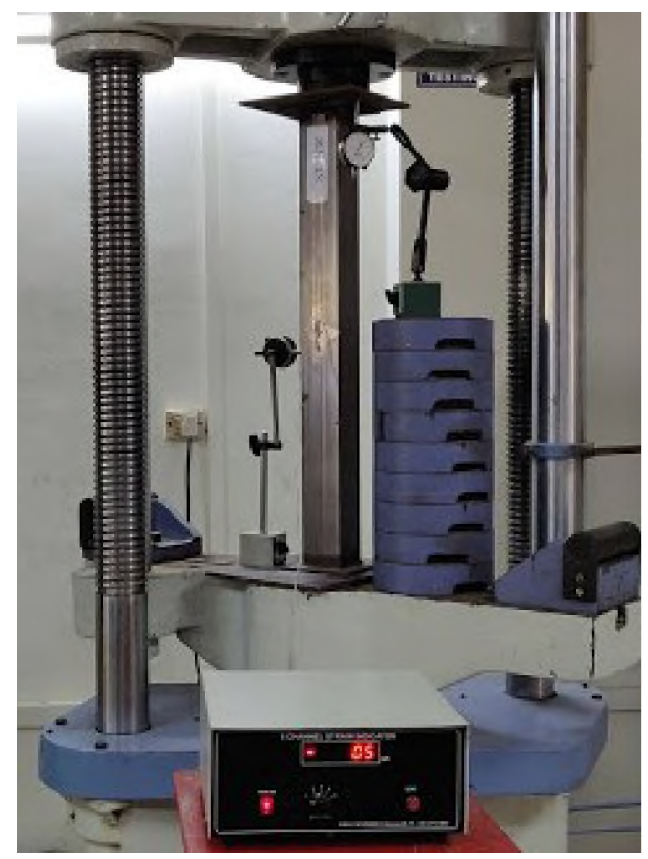

Fig. 3. Test set-up of the CFS wrapped column specimen

\section{Finite element modelling}

\subsection{Model description}

The 3D FE models of the column specimen with GFRP strip were built using the commercially available software ANSYS. The SOLID 185 and SHELL181 from the element library were used to model the steel tube and GFRP strip respectively[12]. The SHELL element with 6 DOF was used to mesh the specimens. The GFRP wrapped columns were assigned with the material properties obtained from the experimental study to validate the results. To define plastic hardening of the built-up columns, the Von Mises yield surface was used. An axial load was applied at the centre of the top plate, thus load distribution to the specimen, as pressure at the top of the column. The coupling option was used to connected the nodes between steel and GFRP Figure 4 shows the mesh model of the square and circular columns with intermediate wrap and end wrap of GFRP.

The pin-end support conditions in terms of displacement and rotation are simulated in the FEA through a reference point both at the top and bottom plate. The translations along $x, y$ and $z$ were constrained against the top end of the plates. The load was applied in increments as sub-steps using Newton-Raphson method from ANSYS library. The overall imperfection was taken as $1 / 1000$ of the overall length of the column, including both the initial bending of the member and initial eccentricity of the loading. For each incremental step of end-shortening, the total reaction at the end is obtained Using, 'UPGEOM' command in ANSYS, buckling mode was obtained.
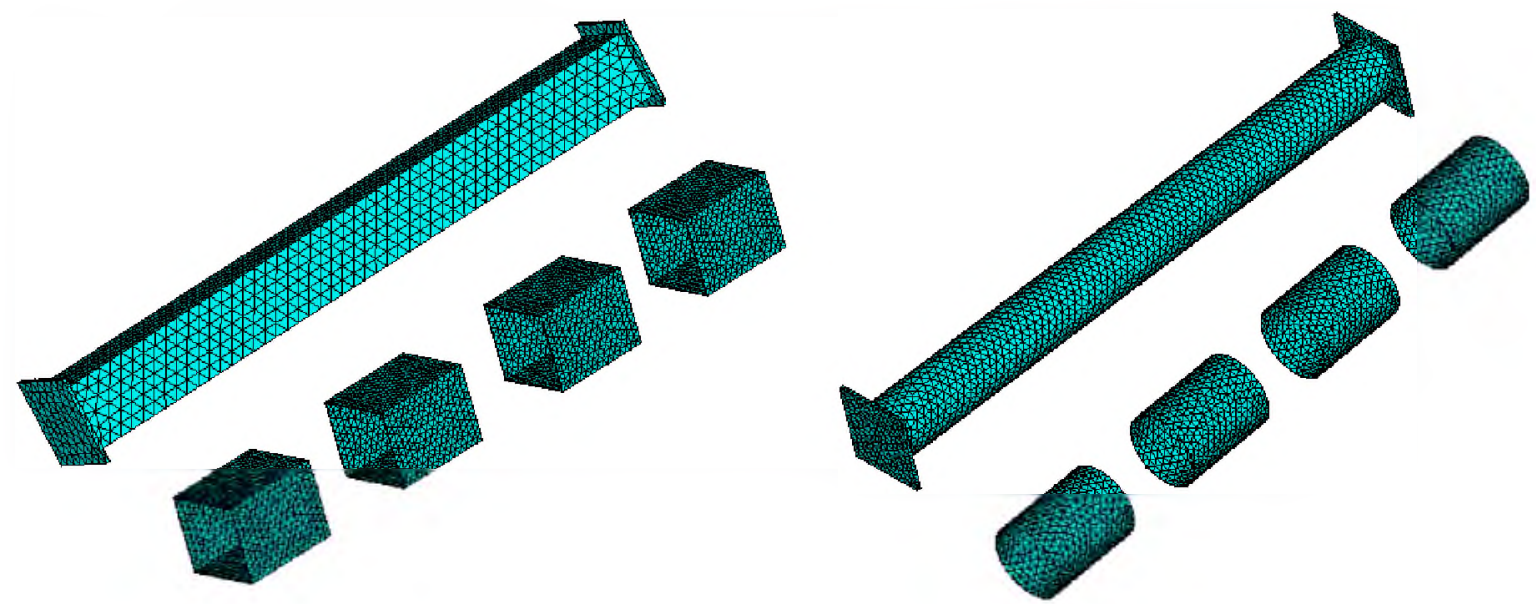

Fig. 4. Mesh model of the column specimen with $I W$ and $E W$ 


\section{Result and Discussion}

\subsection{Effect of cross section on GFRP effectiveness}

Table 2 gives the experimental results and its comparison. From Table 2, it was found that the strength enhancement of the square and circular tubular columns was $24 \%$ and $5 \%$ respectively as compared to unwrapped columns. The stiffness is the ratio of yield load and corresponding axial deformation, and it was calculated that the stiffness of the circular column was more than the square column with GFRP wrapping. For circular cross-section, the stiffness of the specimens CT - 1 IW, CT - 2 IW, CT - 1 IW - EW, and CT - $2 \mathrm{IW}$ - EW were higher and effective to resist the axial deformation and overall buckling. The Square specimens ST - $2 \mathrm{IW}, S T-E W, S T-2 \mathrm{IW}-E W$, and ST FW were able to resist the axial deformation and local buckling, since the stiffness of the specimens is more. Thus the column specimens wrapped with GFRP at intermediate and end portion are effective against local and flexural buckling.
Figure 5 shows the variation of the maximum loadcarrying capacity of the square and circular column specimen wrapped with GFRP strip and unwrapped column. Figure 5 shows that axial strength of the square and circular control specimen without wrapping resist the same load but failure mode of the specimen was different. With the change of cross-section from circular to square tubular column, the percentage increase in the ultimate load-carrying capacity was about $16 \%$ for both wrapped and unwrapped columns. The specimens ST-EW and CT-EW wrapped at the end are able to resist more load of $200 \mathrm{kN}$ and $157 \mathrm{kN}$ respectively. The yield point of the column specimens was observed at $70 \%$ of the peak load. The stiffness of the column specimens was calculated by dividing the yields strength. From the ultimate load-carrying capacity of all the specimens, it was found that the specimens with intermediate wrap and combination of end wrap with intermediate wrap were nearly equal to capacity obtained from the specimen which was fully wrapped with GFRP. From this study, it is concluded that optimum spacing between the fiber strip can be $100 \mathrm{~mm}$ to $200 \mathrm{~mm}$ with end strips to enhance the load carrying capacity of the GFRP wrapped columns.

Table 2. Comparison between the experimental results

\begin{tabular}{|c|c|c|c|c|c|c|c|}
\hline Specimen ID & $\begin{array}{l}\text { Yield } \\
\text { load } \\
\left(P_{Y}\right) \\
\\
(k N) \\
\end{array}$ & $\begin{array}{c}\text { Ultimate } \\
\text { buckling } \\
\text { load }\left(P_{U}\right) \\
(\mathrm{kN})\end{array}$ & $\begin{array}{c}\text { Ulimate } \\
\text { buckling } \\
\text { resistance } \\
\left(\mathrm{Fu}_{\mathrm{U}}\right) \\
\left(\mathrm{kN} / \mathrm{mm}^{2}\right)\end{array}$ & $\begin{array}{c}\text { Axial } \\
\text { shortening } \\
\text { yield load } \\
(\Delta y) \\
(\mathrm{mm})\end{array}$ & $\begin{array}{c}\text { Axial } \\
\text { shortening at } \\
\text { ultimate load } \\
(\Delta \cup) \\
(\mathrm{mm}) \\
\end{array}$ & $\begin{array}{l}\text { Ratio } \\
\frac{F_{U}}{F_{O}}\end{array}$ & $\begin{array}{c}\text { Stiffness } \\
\frac{P_{Y}}{\Delta_{Y}} \\
(\mathrm{kN} / \mathrm{mm})\end{array}$ \\
\hline ST - NW & 110 & 155 & $0.265(\mathrm{Fo})$ & 1.72 & 2.87 & - & 63.95 \\
\hline ST $-1 \mathrm{IW}$ & 133 & 190 & 0.325 & 1.43 & 2.97 & 1.226 & 76.92 \\
\hline$S T-2 I W$ & 133 & 190 & 0.325 & 1.02 & 2.50 & 1.226 & 107.84 \\
\hline$S T-E W$ & 140 & 200 & 0.342 & 1.30 & 3.35 & 1.290 & 84.62 \\
\hline$S T-1 \mathrm{IW}-E W$ & 133 & 190 & 0.325 & 1.63 & 3.30 & 1.226 & 67.48 \\
\hline$S T-2 I W-E W$ & 133 & 190 & 0.325 & 0.95 & 2.35 & 1.226 & 115.79 \\
\hline ST - FW & 133 & 190 & 0.325 & 1.15 & 2.60 & 1.226 & 95.65 \\
\hline $\mathrm{CT}-\mathrm{NW}$ & 105 & 150 & $0.327(\mathrm{Fo})$ & 2.30 & 6.40 & - & 47.83 \\
\hline$C T-1 I W$ & 106 & 152 & 0.332 & 0.28 & 5.00 & 1.013 & 400.00 \\
\hline$C T-2 \mathrm{IW}$ & 109 & 155 & 0.338 & 0.51 & 5.60 & 1.033 & 215.69 \\
\hline CT - EW & 110 & 157 & 0.342 & 2.00 & 6.45 & 1.047 & 55.00 \\
\hline$C T-1 \mathrm{IW}-\mathrm{EW}$ & 110 & 160 & 0.349 & 1.00 & 6.25 & 1.067 & 110.00 \\
\hline CT - 2IW - EW & 110 & 160 & 0.349 & 0.11 & 5.80 & 1.067 & 1000.00 \\
\hline $\mathrm{CT}-\mathrm{FW}$ & 110 & 160 & 0.349 & 1.36 & 4.77 & 1.067 & 80.88 \\
\hline
\end{tabular}

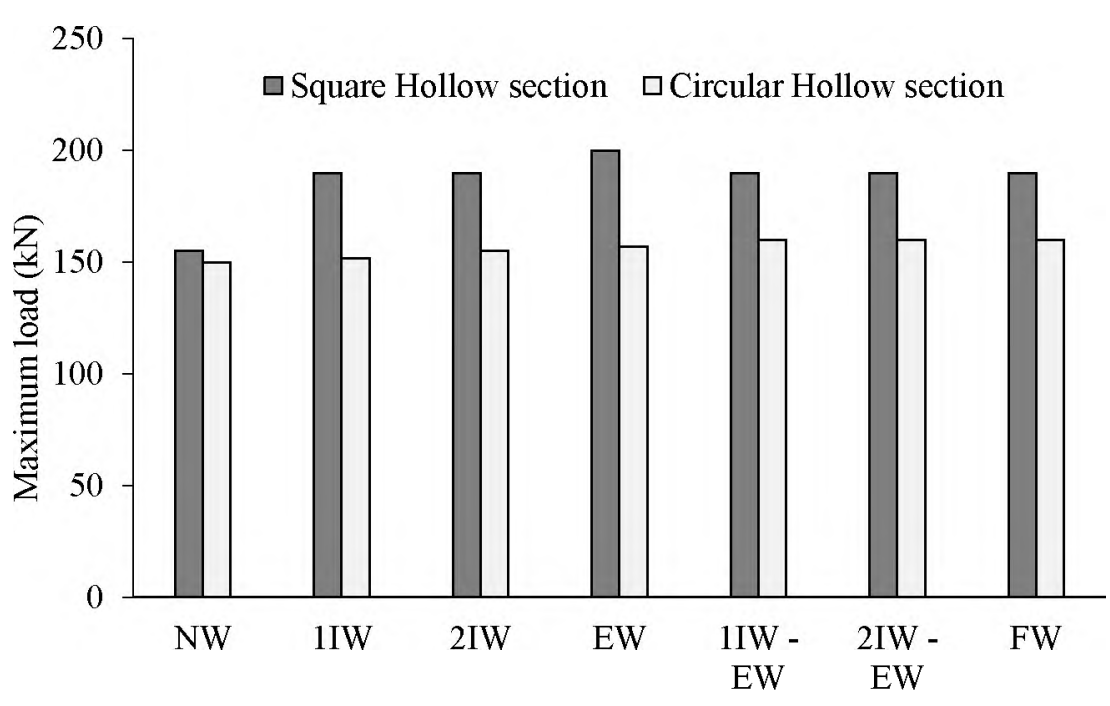

Column specimen

Fig. 5. Comparison between the strength of the square and circular columns wrapped with GFRP 


\subsection{Load-axial deformation behaviour}

The typical axial load-axial deformation characteristics for the column specimens tested are shown in Figures 6\&7, which gives the comparison of the square and circular sections with GFRP strips at the end and intermediate position. The axial deformation was recorded from the dial gauge with the least count of $0.01 \mathrm{~mm}$. The curves describe the influence of the fibre strip at the end and intermediate on the axial deformation. The presence of strip at the end and interemediate location reduces the overall buckling of the column specimens. From figure 6 , it was found that stiffness of the specimen ST - 2IW-EW was more than the specimen which is fully wrapped specimen ST - FW. The load-axial deformation behaviour of the column specimens differs according to the cross-section and position of the GFRP strip. The slopes of the load-deformation curves, for the square and circular specimen also differ based on the fibre position. It is observed from figure7, specimen CT - 2IW EW and CT - 1IW - EW are stiffer than the circular column wrapped fully (CT - FW).

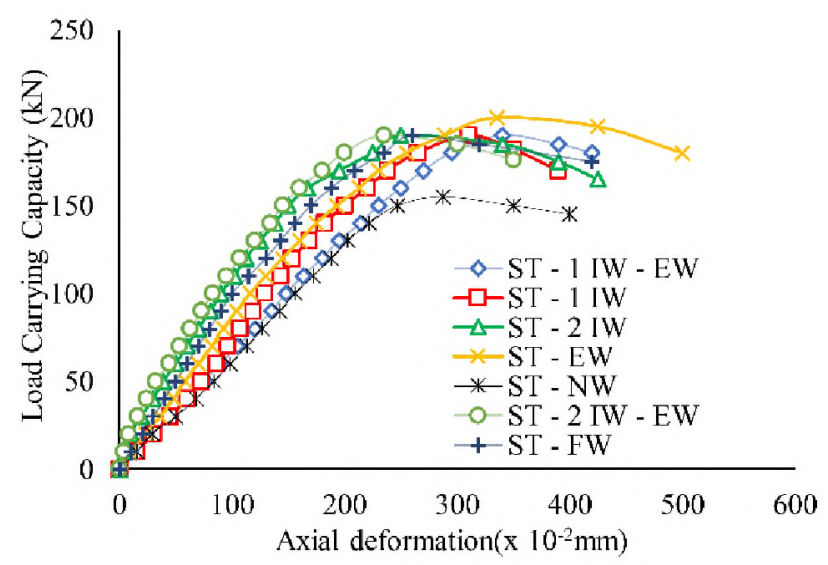

Fig. 6. Load-axial deformation of cold-formed steel square hollow column strengthens with GFRP strip

Figure 8 shows the comparison between experimental and analytical behaviour of the load-deformation behaviour of the circular and square tubular column without GFRP wrapping (CT-NW \& ST-NW). From Figure 8, it was observed that the finite element developed using ANSYS was able to predict the load versus axial deformation

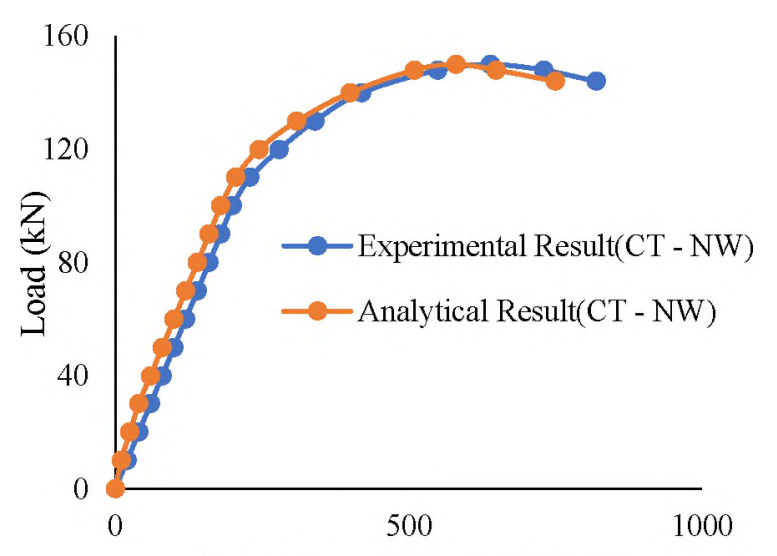

Axial Deformation(x $\left.10^{-2} \mathrm{~mm}\right)$ behaviour of the unconfined column accurately. The FEM model closely predicts the experimental behaviour, thus providing a good correlation against experimental behaviour.

\subsection{Load-strain behaviour}

The axial load plotted against the axial strain of GFRP strip strengthened column specimens are shown in Figures $9 \& 10$ for square and circular cross-section respectively. The strain values were recorded using strain gauge fixed at the midheight of the specimens. At average strain values of 0.0019 , it was observed that all the specimens were initiated to buckle laterally. From Figure10, the strain value decreases for the specimens like CT -FW, CT - 2IW, and CT - EW, thus the confinement pressure of GFRP reduces the strain when compared to the unconfined specimen. The specimen with GFRP sheets confines and provides resistant against both axial and lateral deformation, thereby increasing the resistance against axial deformation of the confined specimen. Once the strain reaches beyond the ultimate tensile strain of the fibre, the specimen mainly fails by GFRP rupture at the end strip both in square and circular crosssection.

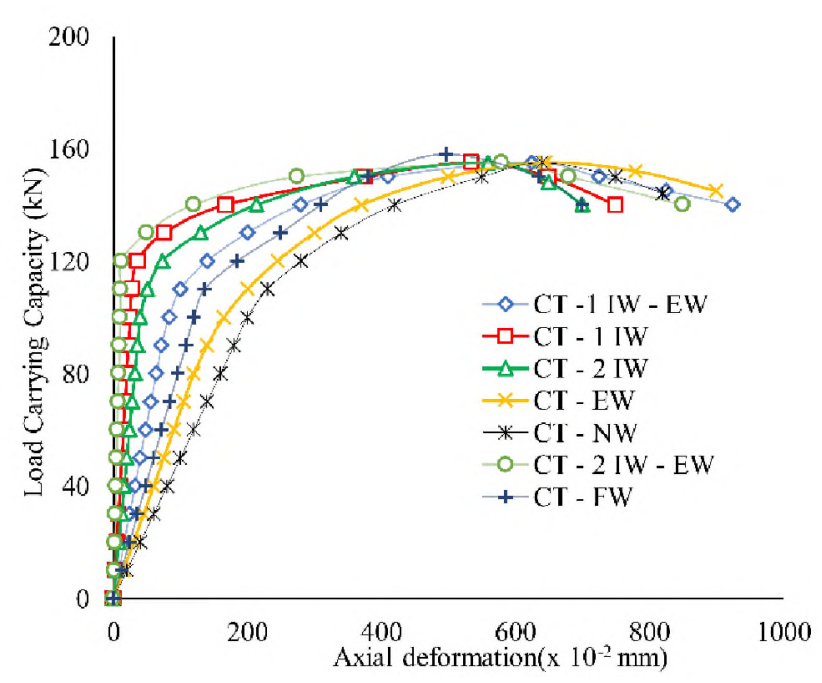

Fig. 7. Load-axial deformation of cold-formed steel circular hollow column strengthens with GFRP strip

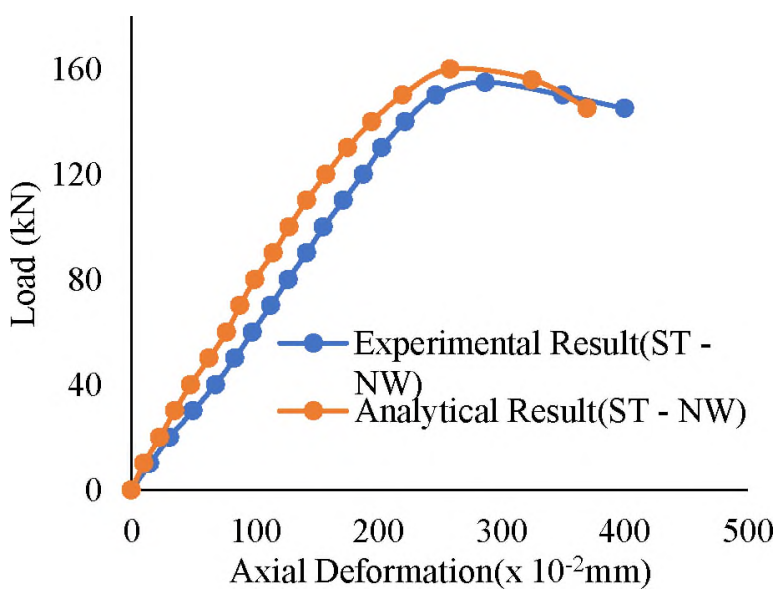

Fig. 8. Comparison between the experimental and analytical load-deformation behaviour (CT-NW \& ST-NW) 


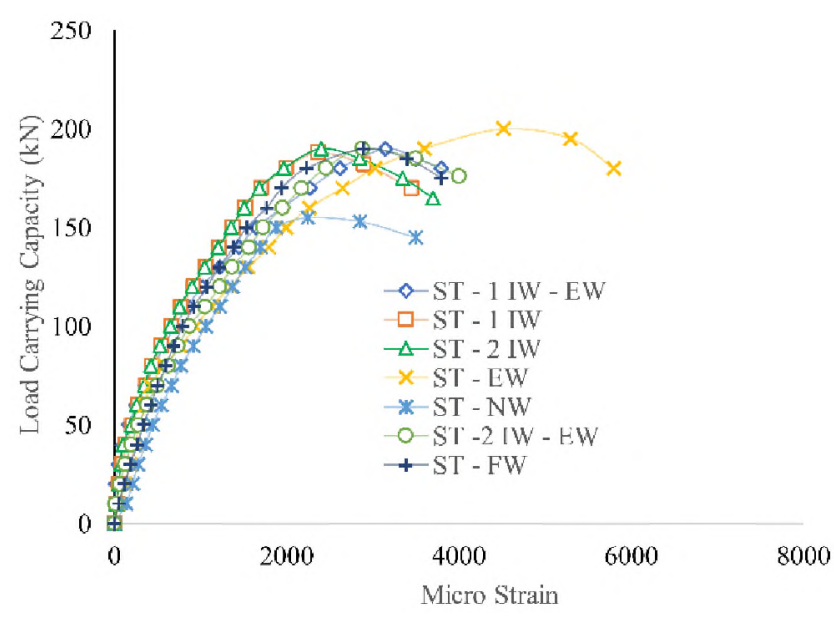

Fig. 9. Load-Micro strain of cold-formed steel square hollow column strengthens with GFRP strip

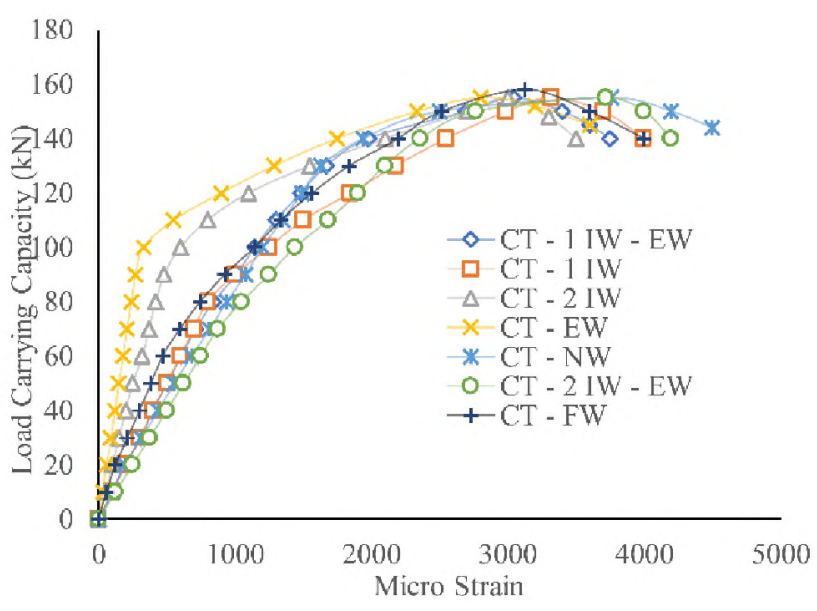

Fig. 10. Load-Micro strain of cold-formed steel circular hollow column strengthens with GFRP strip

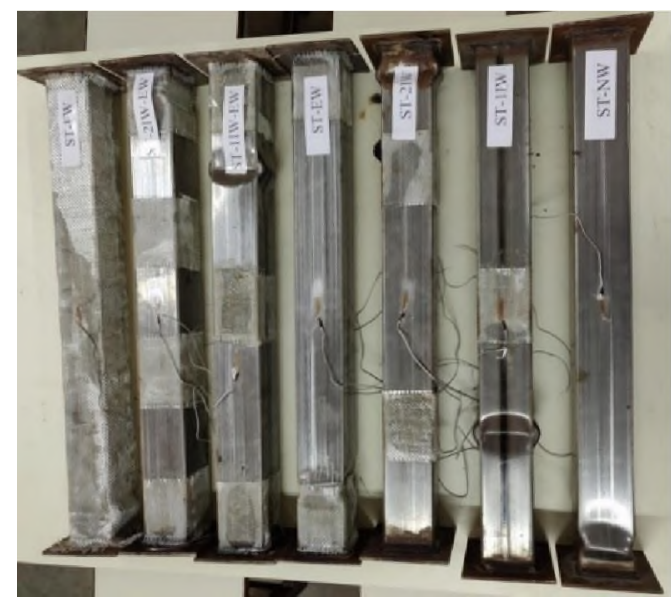

(a)

\subsection{Failure Mode}

All the column specimens with different positions of the GRFP strip were tested to failure under compressive load. Figure 11(a) shows the specimens with square cross-section experienced local buckling namely Elephant - foot failure at the top and bottom of the specimens[16]. In this kind of failure, the depth and breadth of the square section became wider. The local buckling in the square cross-section was observed at two opposite faces, buckled inward and buckled outward as mentioned in Figure 1. The specimen ST - NW and ST - FW fails at the base of the specimen by local buckling. For the specimens with end strip of GFRP i.e. ST $E W$, and ST - 1IW - EW, failure of the specimen occurred at one-fourth column height as outward buckling. It is also observed from the Figure 11(a) the specimens without end strip, fails at different locations, it mainly depends on the clear spacing between the intermediate strip. Near the corners it was observed that the GFRP delaminated from the steel at the place of buckling [2].

In all GFRP wrapped circular specimens, failure occurred mainly by overall buckling of the specimen and followed by the local buckling in the compression zone near the midheight of the CT - NW and CT - FW specimen as shown in Figure 11(b). The overall buckling gets reduced in the fully GFRP specimen as compared to the no-wrap specimen, which implies GFRP retard or reduce the failure. The circular column specimen with end strip fails both by flexural and local buckling. The position of the local buckling was at onefourth height of the specimen for all the specimens wrapped at the end (CT - EW, CT - IIW - EW and CT - 2IW - EW). The column specimens with intermediate strip alone (CT $1 \mathrm{IW}$ and CT - 2IW) fail both by flexural and local buckling at one-third height of the column and the top on to the compression side. All the specimens confined with GFRP strip were analysed using ANSYS and the deformed shape of the column specimens (experimental and analytical) are shown in Figures 12(a) \&12(b). The analytical results were validated with the test results and good agreement between the experimental and analytical mode were achieved [17].

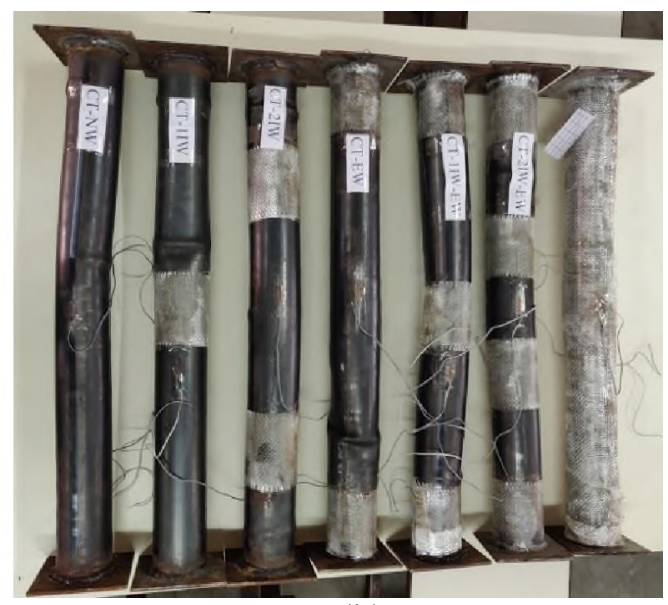

(b)

Fig. 11. Specimens after test 

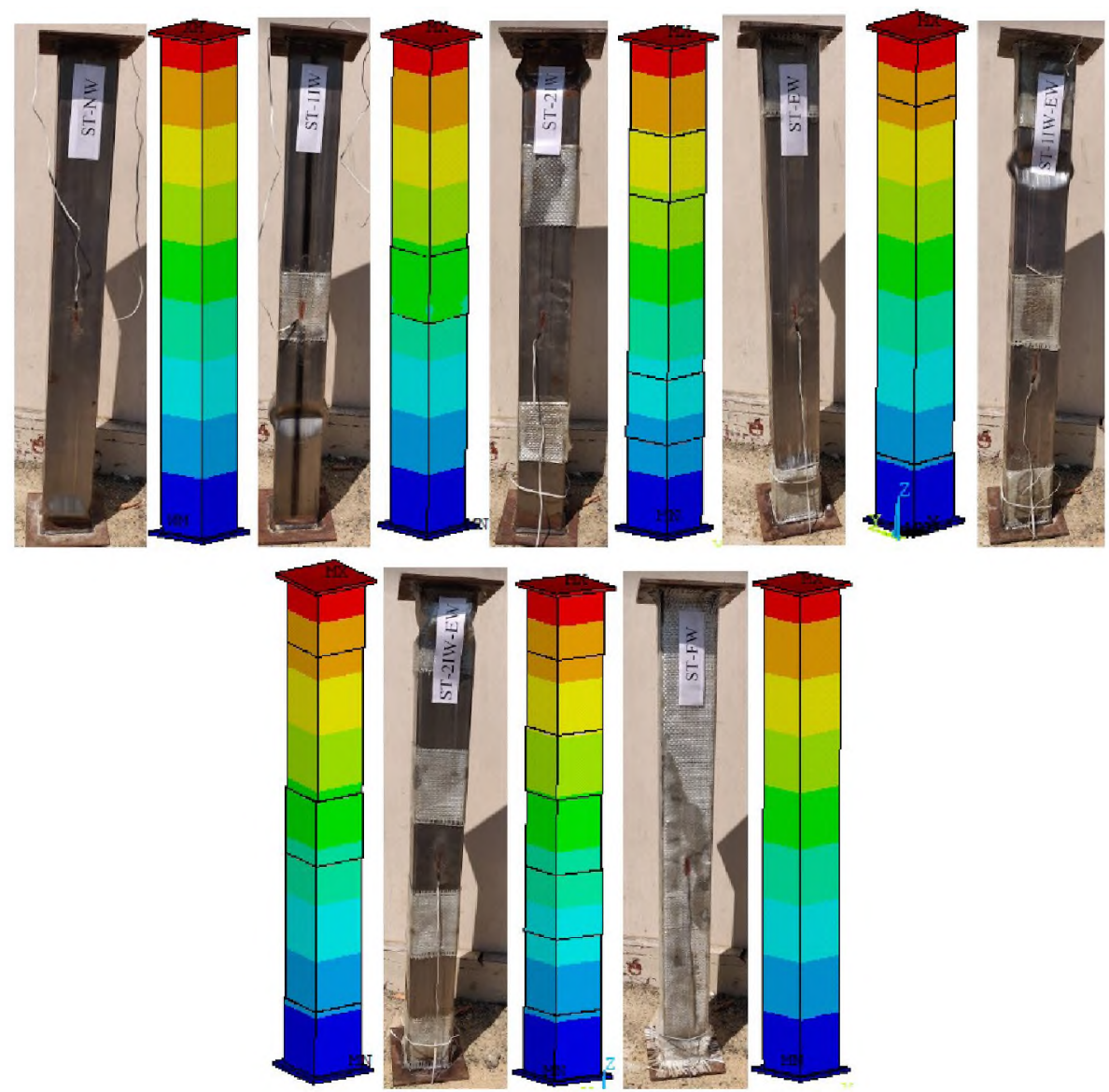

(a) Square Column with GFRP strip

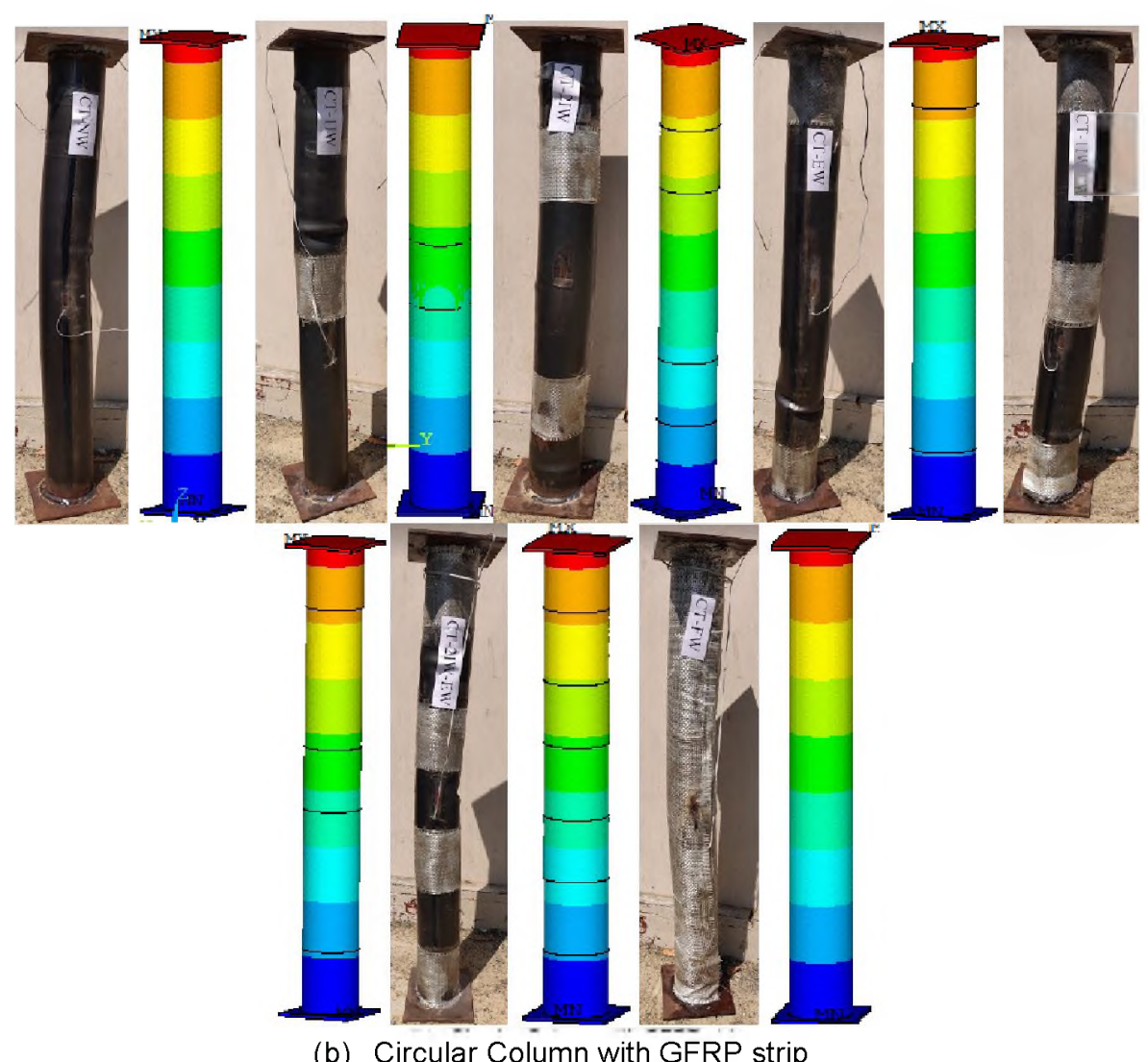

Fig. 12. Deformed shape of the fibre strengthened specimens 
Table 3. Summary of the experimental and FEM results

\begin{tabular}{|c|c|c|c|c|c|c|c|}
\hline Specimen ID & $\begin{array}{l}P_{E X P} \\
(k N)\end{array}$ & $\begin{array}{c}\text { PANSYS } \\
(\mathrm{kN})\end{array}$ & $\frac{P_{\text {ANSYS }}}{P_{\text {EXP }}}$ & $\begin{array}{l}\Delta_{\mathrm{EXP}} \\
(\mathrm{mm})\end{array}$ & $\begin{array}{c}\triangle_{\text {ANSYS }} \\
(\mathrm{mm})\end{array}$ & $\frac{\Delta_{\text {ANSYS }}}{\Delta_{\text {EXP }}}$ & $\begin{array}{l}\text { Failure } \\
\text { Mode }\end{array}$ \\
\hline ST - NW & 155 & 160 & 1.03 & 2.87 & 2.59 & 0.90 & $\bar{L}$ \\
\hline$S T-1 I W$ & 190 & 195 & 1.03 & 2.97 & 2.27 & 0.89 & L \\
\hline$S T-2 \mathrm{IW}$ & 190 & 197 & 1.04 & 2.50 & 2.25 & 0.90 & $L$ \\
\hline ST - EW & 200 & 205 & 1.03 & 3.35 & 3.01 & 0.90 & L \\
\hline ST - 1IW - EW & 190 & 199 & 1.05 & 3.30 & 2.94 & 0.89 & L \\
\hline ST - 2IW - EW & 190 & 201 & 1.06 & 2.35 & 2.22 & 0.94 & L \\
\hline ST - FW & 190 & 205 & 1.08 & 2.60 & 2.17 & 0.83 & $\mathrm{~L}$ \\
\hline Mean & & & 1.044 & & & 0.895 & \\
\hline Std Deviation & & & 0.020 & & & 0.032 & \\
\hline cov & & & 1.871 & & & 3.601 & \\
\hline $\mathrm{CT}-\mathrm{NW}$ & 150 & 160 & 1.07 & 6.40 & 5.81 & 0.91 & $F+L$ \\
\hline$C T-1 \mathrm{IW}$ & 152 & 162 & 1.07 & 5.00 & 4.85 & 0.97 & $F+L$ \\
\hline$C T-2 \mathrm{IW}$ & 155 & 165 & 1.06 & 5.60 & 4.35 & 0.83 & L \\
\hline CT - EW & 157 & 160 & 1.02 & 6.45 & 5.27 & 0.82 & $\mathrm{~L}$ \\
\hline CT - 1IW - EW & 160 & 164 & 1.03 & 6.25 & 5.38 & 0.92 & $F+L$ \\
\hline CT - 2IW - EW & 160 & 166 & 1.04 & 5.80 & 4.78 & 0.92 & $F+L$ \\
\hline $\mathrm{CT}-\mathrm{FW}$ & 160 & 171 & 1.07 & 4.77 & 3.97 & 0.91 & $F+L$ \\
\hline Mean & & & 1.050 & & & 0.896 & \\
\hline Std Deviation & & & 0.022 & & & 0.054 & \\
\hline $\mathrm{COV}$ & & & 2.067 & & & 6.030 & \\
\hline
\end{tabular}

$\mathrm{F}=$ Flexural Buckling; $\mathrm{L}=$ Local Buckling

The test ultimate load values ( $\left.P_{\text {EXP }}\right)$ were quite close to the ultimate load values ( $P_{\text {ANSYS }}$ ) obtained for the finite element analysis as shown in Table. 3. The mean and standard deviation of the $P_{\text {ANSYS }} / P_{\text {EXP }}$, read as $1.044 \& 0.02$ for SHS and $1.050 \& 0.022$ for CHS. Similarly, the ratio of axial deflection observed between the test and FEM ( $\triangle$ ANSYS $/ \Delta$ EXP) read the mean and standard deviation as 0.895 \& 0.032 for SHS and $0.896 \& 0.054$ for $\mathrm{CHS}$.

\section{Conclusions}

In this paper, the effect of strengthening the cold-formed steel square and circular column using GFRP strip were investigated both in the experimental and analytical studies. A series of fourteen tests of cold-formed steel tubular sections with externally bonded GFRP strips was conducted to study the strength and buckling behaviour of tubular member. The analytical study using ANSYS was carried out and validated using the experimental results. The effect of GFRP strips at different locations and their behaviour were compared. The conclusions derived from this study are as follows.

1. The square tubular columns and circular tubular columns fail by local and global buckling.

2. The GFRP strips at the ends with one or two intermediate strips delay the local buckling and they occur at one-third and one-fourth height of the column of the specimen with one intermediate and two intermediate strips along with the end strip respectively.

3. The percentage increase in the strength was $16 \%$ for change of cross-section from circular to square tubes.
The square and circular column specimens with GFRP strip at ends can resist more load of $200 \mathrm{kN}$ and $157 \mathrm{kN}$ respectively

4. The strength enhancement of the square and circular tubular columns was $24 \%$ and $5 \%$ respectively as compared to unwrapped columns.

5. The stiffness of the square and circular tubular column with end and the intermediate strip was more than the specimens with fully wrapped specimens, which gives confidence of using GFRP strips at specific location instead wrapping fully and it also reduces the amount of fiber usage.

6 . The results indicate that the ultimate buckling resistance with intermediate and end GFRP strips is sensitive to the cross-sectional area of the tubular section that causes local and global buckling of the columns under axial compression

7. Once the strain reaches beyond the ultimate tensile strain of the fibre, all the specimens mainly fail by GFRP rupture at the end strip both in square and circular crosssection. The rupturing of the fibre was not observed for the specimens with the intermediate strip.

8. The finite element model developed for the wrapped column specimen in the study, predicts the strength accurately with the mean and standard deviation of 1.047 and 0.020 respectively.

\section{Acknowledgment}

The authors would like to thank the Management and Principal, Sri Sivasubramaniya, Nadar College of Engineering, Chennai, India 


\section{References}

[1] Bambach, M. R., Jama, H. H., \&Elchalakani, M. (2009)Axial capacity and design of thin - walled steel SHS strengthened with CFRP. Thin-Walled Struct47(10): 1112-1121.

[2] Fernando, D., Yu, T., Teng, J, G., \& Zhao, X, L. (2009)CFRP strengthening of rectangular steel tubes subjected to end bearing loads: Effect of adhesive properties and finite element modelling. Thin-Walled Struct47(10): 1020-1028.

[3] Jiao, H., \& Zhao, X, L. (2004)CFRP strengthened butt - welded very high strength (VHS) circular steel tubes. Thin-Walled Struct42(7), 963-978.

[4] Fawzia, S., Al-Mahaidi, R., Zhao, X, L., \&Rizkalla, S., (2007)Strengthening of circular hollow tubular sections using high modulus CFRP sheets. Constr Build Mat 21(4):839-845.

[5] Jimmy Haedir, S., \& Xiao- Ling Zhao., (2011)Design of Short CFRP-reinforced steel tubular columns. JConstrSteel Res 67(3):497-509.

[6] Zhao, X.L., \& Zhang Lei, (2007)State-of-the-art review on FRP strengthened steel structures. EngStruct, 29(11):1808-1823.

[7] Hongyuan Tang., Canjun Wang \&Ruijiao Wang, (2016)Enhancing Stability of Thin- Walled short steel channel using CFRP under eccentric compression. IntJPolymer Science, 2016(2790385):1-11.

[8] Teng, J.G., Yu, T., \& Fernando, D., (2012)Strengthening of steel structures with fiberreinforced polymer composites. JConstrSteel Res78(11):131-143.

[9] Silvestre, N., Young, B., \&Camotim, D. (2008)Nonlinear behaviour and load-carrying capacity of CFRPstrengthened lipped channel steel columns. Eng Struct, 30(10):2613-2630.
[10] Punitha Kumar A., \& Senthil R (2016)Behaviour of CFRP strengthened CHS under axial static and axial cyclic loading. KSCE J CivEng20(4):1493-1500.

[11] Punitha Kumar A., \& Senthil R (2016)Axial Behaviour of CFRP-Strengthening circular steel hollow sections. Arab J SciTech41(4):3841-3850.

[12] Jai -Woo Park, Hee-JinYeom\& Jung-Han Yoo (2013)Axial loading tests and FEM analysis of slender square hollow section (SHS) stub columns strengthened with carbon fiber reinforced polymers. Arab J Sci Tech 13(4):731-743.

[13] Amr Shaat\& Amir Z. Fam (2009)Slender steel columns strengthened using high-modulus CFRP plates for buckling control. JComp Constr 13(1):2-12.

[14] Masoumeh Karimian, KambizNarmashiri, Mehdi Shahraki\& Omid Yousefi (2017)Slender steel columns strengthened using high-modulus CFRP plates for buckling control. JConstrSteel Res 138(11):555-564.

[15] Dabaon, M., Ellobody, E., \&Ramzy, K. (2015) Experimental investigation of built-up cold-formed steel section battened columns. Thin-Walled Struct 92:137145.

[16] Davison, B., \& Owens, G. W. (Eds.). (2011)Steel designers' manual. New York: Wiley.

[17] Nuno Silvestre., Dinar Camotim\& Ben Young, (2009)On the use of the EC3 and AISI specifications to estimate the ultimate load of CFRP-strengthened coldformed steel lipped channel columns. Thin-Walled Struct 47(10): 1102-1111. 